\title{
Changes of anaerobic to aerobic conditions but not of crop type induced bulk soil microbial community variation in the initial conversion of paddy soils to drained soils
}

\author{
Xiaoqin Dai *, Ye Yuan, Huimin Wang \\ Qianyanzhou Ecological Station, Key Laboratory of Ecosystem Network Observation and Modeling, Institute of Geographic Sciences and Natural Resources Research, Chinese Academy of Sciences,
} Beijing 100101, People's Republic of China

\section{A R T I C L E I N F O}

\section{Article history:}

Received 16 February 2016

Received in revised form 23 May 2016

Accepted 8 August 2016

Available online 15 August 2016

\section{Keywords:}

Double cropping system

Land use conversion

Phospholipid fatty acid (PLFA)

Red soil

Soil properties

Subtropical China

\begin{abstract}
A B S T R A C T
Soil microorganisms are the main drivers of all of the biochemical processes that occur in soils. Land-use conversion, a common occurrence driven by market economy, changes plant species and the associated management strategies, thus significantly influences soil microbial communities. However, few studies have been conducted to disentangle the effect of the alteration of plant species from that of soil environment during the initial years of conversion. In this study, the effect of land-use conversion from double rice cropping (RR) to maize-maize (MM) and soybean-peanut (SP) double cropping systems on soil physical and chemical properties and microbial communities was studied two years after the conversion in southern China. The results showed that land use conversion significantly changed the soil properties, microbial communities and microbial biomass. The soil water content decreased significantly by $26.3 \%$, and the $\mathrm{pH}$ decreased by 0.50 and 0.52 for MM and SP, respectively, compared with RR. Soil inorganic N also decreased significantly by $55 \%$ after the conversion to drained fields. The total phospholipid fatty acids (PLFAs), and bacterial, G+, G- and actinomycetic PLFAs decreased significantly after the conversion. No significant differences were found in the soil properties, microbial communities and microbial biomass between the converted MM and SP. Our results indicated that the changes of anaerobic to aerobic conditions, rather than of crop type, induced the variations in the soil properties and microbial communities during the initial years after conversion from paddy soils to drained soils. In particular, soil pH was the key factor that regulated the variations in the soil microbial communities after conversion.
\end{abstract}

(c) 2016 Elsevier B.V. All rights reserved.

\section{Introduction}

Soil is an important component of terrestrial ecosystems and plays a crucial role in plant productivity and ecosystem services. Soil microorganisms are involved in all of the biochemical processes that occur in soils, and play an important role in organic matter decomposition, nutrient transformation and cycling, and trace gas emission (Creamer et al., 2015). Land use conversion, particularly within cropland, is a common occurrence driven by market economy (Houghton et al., 1999). The alteration of land use changes plant species, the associated management strategies and disturbance intensity, and thus strongly influences soil physicochemical properties, soil microbial biomass and community composition (Bossio et al., 2005; Lauber et al., 2008; Nishimura et al., 2008; Wang et al., 2014). However, few studies have been conducted to identify the effects of the changes in plant species and in soil environment.

\footnotetext{
* Corresponding author.

E-mail address: daixq@igsnrr.ac.cn (X. Dai).
}

Previous studies have shown that shifts in the soil microbial community structure can be associated with changes in a number of soil properties, including the soil water content (Yang and Zhang, 2014; Yuan et al., 2015), the soil total phosphorus, available phosphorus (Sheng et al., 2013), $\mathrm{NO}_{3}-\mathrm{N}$, and soil organic carbon contents, $\mathrm{pH}$ (Sheng et al., 2013; Yang and Zhang, 2014; Yuan et al., 2015), and so on. The different relationships between microbial communities and soil properties are mainly affected by land use type and land use history (Lisboa et al., 2014) and has been shown to be site-specific (Williams et al., 2013). The development of different plant species associated with land use conversion would have different influences on soil microbial communities in the rhizosphere, which depends on the differences in the quantity and quality of carbon resources different plant species produce (Sanon et al., 2009). It is crucial to differentiate the effects of plant species from soil environment for carbon and nitrogen cycle modeling and agriculture production management. However, there is conflicting evidence of plant influences on bulk soil across individual fields (Jangid et al., 2011).

Land use conversion results in dynamic changes in soil processes (Arevalo et al., 2011). For example, Alberti et al. (2010) showed that there was a net loss of carbon in terms of net biome production 
2 years after conversion from corn to alfalfa, but this difference decreased over the next few years (Robertson et al., 2000). Sun et al. (2011) suggest an initial increase in soil nutrients (SOC and total N) within 10 years after rice conversion to vegetables, followed by stability in the nutritional status during an extended period of vegetable cultivation between 10 and 100 years. Land use conversion can have significant and long-lasting effects on soil properties and microbial communities (Murty et al., 2002). Consequently, the understanding of the conversion effects at different timescales is important and urgently required. However, little research has been conducted to understand the effect on soil properties and microbial communities during the initial years after land conversion.

Rice is the second most important crop in the world after wheat and is the most important crop in China. The rice area in China accounts for approximately $19 \%$ of the global rice area and plays an important role in China's food security and agricultural production (Zhang et al., 2005). However, in recent years, a considerable quantity of rice fields has been converted to maize, soybean and vegetable fields due to water shortages and economic benefits (Nishimura et al., 2008; Sun et al., 2011; Yuan et al., 2016). For example, in the Huai river basin in northern China, the main crops approximately 20 years ago were winter wheat and lowland rice (in summer); however, farmers started replacing lowland rice with crops such as maize, soybean, and cotton because of increasing water shortages (Tong et al., 2003). However, few studies have been carried out to compare the soil properties and microbial community composition between double rice paddies and maize or soybean fields, especially for newly established drained fields. After land use conversion from a paddy to a drained field, the soil environment changes from anaerobic to aerobic; this significantly influences the soil water content and soil pH, which have profound effects on the soil microbial community (Wang et al., 2014). Moreover, converted drained fields have been planted to many different types of crops (Nishimura et al., 2008), which would also influence the soil microbial community. However, few studies have focused on converted crop types to determine how they influence the soil microbial community. It is important to distinguish between the effects of the changes of anaerobic to aerobic conditions and of crop type conversion on the soil microbial community to develop sustainable agriculture.

Accordingly, in this study, we compared the soil properties and microbial communities of double rice (RR) paddies and newly converted maize-maize (MM) or soybean-peanut (SP) fields. The objectives were 1) to identify the variation in the soil properties and soil microbial community structure 2 years after land conversion from RR to MM or SP; and 2) to compare the difference in soil properties and microbial community structure between MM and SP. We hypothesized that 1) recent conversion from paddy fields to drained fields would change the soil properties and microbial communities; 2) conversion to MM and SP would have similar effects on the soil microbial communities in the initial years after land conversion; and 3) pH is the main driver of the variation in the soil microbial communities.

\section{Materials and methods}

\subsection{Site description}

An experimental site was set up at the Qianyanzhou Ecological Station ( $26^{\circ} 44^{\prime} \mathrm{N}, 115^{\circ} 03^{\prime} \mathrm{E}$ ) of the Chinese Academy of Sciences (CAS), located in Jiangxi Province, southern China. The site is a typical red soil, hilly region with a subtropical monsoon climate. The average annual temperature varies between 17.4 and $18.9{ }^{\circ} \mathrm{C}$. Annual precipitation varies between 945 and $2144 \mathrm{~mm}$, with 24\%, 41\%, 23\% and 12\% of the total precipitation occurring in the four respective quarters of the year. The soils (equivalent to Plinthudults in the US Soil Taxonomy) are predominately sand and loam and were formed from alluvial fans of nearby rivers. The soils contain $53.4 \%$ sand, $37.8 \%$ silt and $8 \%$ clay. The topsoil $(0-20 \mathrm{~cm})$ has an organic content of $15.8 \mathrm{~g} \mathrm{~kg}^{-1}$ and a total nitrogen content of $1.35 \mathrm{~g} \mathrm{~kg}^{-1}$, and the soil $\mathrm{pH}$ was 5.35 and the bulk density was $1.30 \mathrm{~g} \mathrm{~cm}^{-3}$ before land conversion.

\subsection{Experimental design}

The experimental fields were continuously cultivated with paddy rice for approximately 30 years. In April 2011, we converted a portion of the rice paddies to drained fields by draining the fields, and the remaining land continued to be cropped with rice. The treatments included 3 rotation systems, i.e., early rice-late rice-fallow (RR), maize-maizefallow (MM) and soybean-peanut-fallow (SP). Each treatment had three replications and the experiment was designed as a randomized complete block. The plot area was $7.6 \mathrm{~m} \times 6.3 \mathrm{~m}$. In the drained fields, the crops were planted on beds that were $1.2 \mathrm{~m}$ wide and $7.6 \mathrm{~m}$ long, with a $0.3-\mathrm{m}$ wide and $7.6-\mathrm{m}$ long furrow between the beds. All crops had a broad range of fertilizer rate according to the local farmers' practices. To control other influencing factors except treatments, all of the

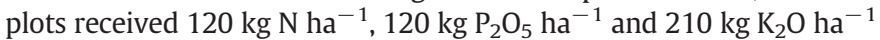
in each growing season. The fertilizers used were urea $(46 \% \mathrm{~N})$, fused calcium/magnesium phosphate $\left(13 \% \mathrm{P}_{2} \mathrm{O}_{5}\right)$, and potassium chloride $\left(60 \% \mathrm{~K}_{2} \mathrm{O}\right)$. The fertilizer was broadcast for the rice and hole-applied for the other crops. Within a growing season, the crop varieties chosen had a similar planting date and growing period. Following the local famers' practices, both of the early rice and late rice was transplanted at spacing of $20 \times 17 \mathrm{~cm}$. Forty percent of the total $\mathrm{N}$ was applied as a basal dressing during land preparation, and other reminder was topdressed seven days after the rice was transplanted. Herbicide was applied in the third day after transplanting in each growing season and hand-weeding in the later growing stage. Maize was sowed with a spacing of $60 \times 27 \mathrm{~cm}$, and $40 \%$ of the total $\mathrm{N}$ was basal-dressed during land preparation and other reminder was top-dressed at the elongation stage. Soybean and peanut was sowed with a spacing of $30 \times 20 \mathrm{~cm}$, and $40 \%$ of the total $\mathrm{N}$ was applied as a basal dressing and other reminder was top-dressed at the fourth trifoliolate development stage. The phosphate and potassium chloride was applied before transplantation or sowing and incorporated during land preparation. The drained fields were sprayed with herbicide 2 days after seeding to prevent the emergence and growth of grass and hand-weeding after crop establishment.

\subsection{Soil sampling and analysis}

Soil samples were collected after crop harvest according to a systematic sampling design along S-shaped transects in July 2013. Five soil cores $(0-20 \mathrm{~cm})$ were collected from every plot, composited and mixed thoroughly. The mulch layer was removed before collecting the cores. Each soil sample was placed in a cooler plastic bag in the field and transported to the laboratory. The soil samples were passed through a 2-mm sieve, mixed and divided into three parts, i.e., for the determination of soil water content; immediate storage at $-20{ }^{\circ} \mathrm{C}$ for phospholipid fatty acid (PLFA) and inorganic $\mathrm{N}\left(\mathrm{NH}_{4}-\mathrm{N}\right.$ and $\left.\mathrm{NO}_{3}-\mathrm{N}\right)$ determination; and air-dried to determine $\mathrm{pH}$ and continued to pass through a $0.149-\mathrm{mm}$ sieve for SOC and TN analyses.

\subsection{Soil physical and chemical properties analysis}

The soil water content was determined using gravimetric methods. The soil $\mathrm{pH}$ was determined in a 1:2.5 soil to water solution using a digital $\mathrm{pH}$ meter. The total organic carbon (SOC) and total soil nitrogen (TN) contents of the dried samples were measured using an elemental analyzer (Elementar, Vario-Max, Germany). The inorganic $\mathrm{N}\left(\mathrm{NO}_{3}-\mathrm{N}\right.$ and $\mathrm{NH}_{4}-\mathrm{N}$ ) concentration was quantified colorimetrically using a flow injection autoanalyzer (AutoAnalyzer 3, Bran + Luebbe, Germany). 
Table 1

Influence of land-use conversion from paddy fields to drained fields on soil physical and chemical properties (means \pm standard error).

\begin{tabular}{|c|c|c|c|c|c|c|}
\hline Land use type & $\begin{array}{l}\text { WHC } \\
(\%)\end{array}$ & $\mathrm{pH}$ & $\begin{array}{l}\mathrm{SOC} \\
\left(\mathrm{g} \mathrm{kg}^{-1}\right)\end{array}$ & $\begin{array}{l}\mathrm{TN} \\
\left(\mathrm{g} \mathrm{kg}^{-1}\right)\end{array}$ & $\mathrm{C} / \mathrm{N}$ & $\begin{array}{l}\text { IN } \\
\left(\mathrm{mg} \mathrm{kg}^{-1}\right)\end{array}$ \\
\hline $\mathrm{RR}$ & $25.3 \pm 0.88 \mathrm{a}$ & $5.12 \pm 0.03 \mathrm{a}$ & $16.1 \pm 0.43 \mathrm{a}$ & $1.44 \pm 0.01 \mathrm{a}$ & $11.2 \pm 0.25 \mathrm{a}$ & $14.2 \pm 3.24 \mathrm{a}$ \\
\hline MM & $18.7 \pm 2.03 b$ & $4.62 \pm 0.02 b$ & $15.3 \pm 0.55 \mathrm{a}$ & $1.32 \pm 0.05 a$ & $11.6 \pm 0.05 a$ & $6.34 \pm 0.28 b$ \\
\hline SP & $18.7 \pm 2.40 \mathrm{~b}$ & $4.60 \pm 0.08 b$ & $15.1 \pm 0.44 \mathrm{a}$ & $1.29 \pm 0.05 a$ & $11.7 \pm 0.15 \mathrm{a}$ & $6.32 \pm 0.46 b$ \\
\hline
\end{tabular}

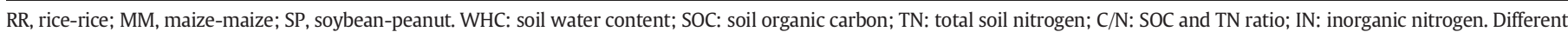
letters within a column indicate significant differences $(P<0.05)$.

\subsection{Phospholipid fatty acid (PLFA) analysis}

The microbial community composition was determined by PLFA analysis (Bossio et al., 1998). Briefly, lipids were extracted from $8 \mathrm{~g}$ of soil using a chloroform:methanol:phosphate buffer mixture (1:2:0.8 $(\mathrm{v} / \mathrm{v} / \mathrm{v}))$ and were separated into neutral lipids, glycolipids and phopholipids using a LC-SiSPE silica column (Anpel Scientific Instrument Co. Ltd., Shanghai, China). The phospholipids were subjected to mild alkaline methanolysis and the fatty acid methyl esters (FAMEs) were identified qualitatively and quantitatively using a Thermo ISQ gas-chromatography mass spectroscopy (GCMS) system (TRACE GC Ultra ISQ) by comparing their relative retention times to 37 commercially available FAMEs (FAME 37 47885-U, Supelco, Inc.) and a mixture of 26 bacterial FAMEs (BAME26 47080-U, Supelco, Inc.). For each sample, the abundance of individual fatty acids was calculated by converting GC peak areas to ng $g^{-1}$ dry soil using an internal standard (19:0). The PLFAs are designated using the nomenclature described in Frostegård et al. (1993).

A total of 16 fatty acids were identified in this study. Biomarkers

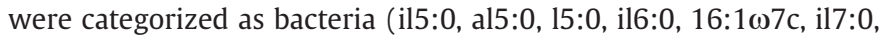

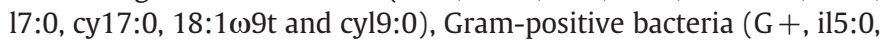

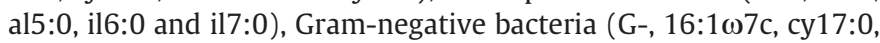

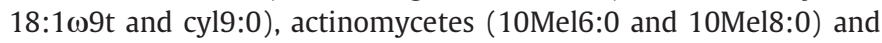

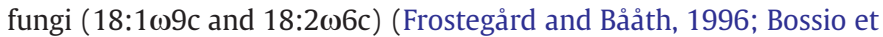
al., 1998). However, it should be noted that these are only general associations, as individual PLFAs do not always strictly correspond to specific bacterial or fungal groups (Frostegård et al., 2011). Individual PLFA biomarkers were expressed using absolute values ( $\mathrm{ng} \mathrm{g}^{-1}$ soil). The sums of the PLFAs were determined as the microbial biomass of specific functional groups using identified PLFAs in each sample. The ratio of specific functional groups and total PLFAs, and fungal and bacterial

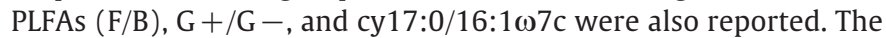
ratios of cyclopropyl fatty acids to their precursors (i.e., cy17:0/ $16: 1 \omega 7 \mathrm{c})$ are indicators of physiological and nutritional stress with-

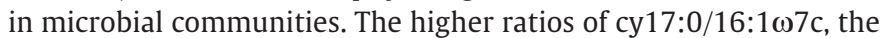
higher physiological and nutritive stress (Moore-Kucera and Dick, 2008).

\subsection{Statistical analysis}

Individual soil properties, microbial functional groups biomass based on PLFAs and the ratio of each specific functional group and total PLFAs, F/B, G+/G-, and cy17:0/16:1 $\omega 7 \mathrm{c}$ were analyzed against land use type (linear mixed effects model with block as a random effect). The analysis of variance was conducted using the SPSS package (version 20.0).

Permutational multivariate analysis of variance (perMANOVA) was employed to test the significance of land conversion and crop type on soil properties using the function "adonis" from the "vegan" package. The difference between the paddy (RR) and drained soils (combined $\mathrm{MM}$ and SP) was considered as the land conversion-induced effect and the difference between MM and SP was considered as the crop type conversion-induced effect. The first perMANOVA analyzed the land conversion effect; the second analyzed the crop type effect (permutations nested within block).
Microbial community composition, based on PLFA ng proportions per $g$ soil, was analyzed using perMANOVA, first against land conversion, second against crop type and third against soil properties (permutations nested within block). The original data matrix of soil properties and microbial community composition were subjected to nonmetric multidimensional scaling analysis (NMDS) using the function "metaMDS" from the "vegan" package. All of the multivariate analyses were performed in $\mathrm{R}$ ( $\mathrm{R}$ Development Core Team, 2009).

\section{Results}

\subsection{Soil physical and chemical properties}

The soil properties varied significantly after the conversion from paddy fields to drained fields (Tables 1 and 2 ), and land conversion explained $67.2 \%$ of the variation. However, no significant difference in the soil properties was found between MM and SP (Tables 1 and 2). The soil water content significantly decreased by $26.3 \%$, and the $\mathrm{pH}$ decreased by 0.50 and 0.52 for MM and SP, respectively, compared with RR. The pH in MM was not significantly different from that in SP. Soil inorganic N also decreased significantly (by 55\%) after the conversion to the drained fields. Land use conversion had no significant effect on the soil SOC, $\mathrm{TN}$ and $\mathrm{C} / \mathrm{N}$.

\subsection{PLFA composition}

The microbial PLFA composition was significantly influenced by the land use conversion (Fig. 1a and Table 2), and the land conversion explained $63.5 \%$ of the variation. However, the PLFA composition was not significantly influenced by crop type (Fig. 1a and Table 2). This is clearly shown in Fig. 1a: the PLFA composition profiles were clearly separated into 2 groups, i.e., the paddy soils (RR), and the drained soils (MM and SP). This indicated that the microbial community profiles were distinctly different after land use conversion from RR to MM and SP, but were similar between MM and SP.

The $\mathrm{ng} \mathrm{g}^{-1}$ soil concentrations of the monounsaturated chain PLFAs

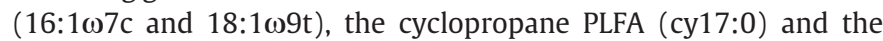
branched-chain PLFAs (i15:0 and a15:0) were at the bottom left of Fig.1b, situating a similar quadrant with the sample from paddy fields in Fig.1a, indicating higher in the paddy fields than in the drained fields. By contrast, the methyl fatty acids (10Me16:0 and 10Me18:0) and $18: 1 \omega 9 \mathrm{c}$ and $18: 2 \omega 6 \mathrm{c}$ were at right of Fig.1b, indicating relatively higher in the drained fields than in the paddy fields (Fig. 1b). The

Table 2

Effect of land use conversion and crop type on soil properties, PLFA composition and microbial functional groups according to the perMANOVA results.

\begin{tabular}{llll}
\hline Variations & $\mathrm{F}$ & $\mathrm{R}^{2}$ & $P$-value \\
\hline Land use conversion-induced & & & \\
$\quad$ Soil properties & 14.37 & 0.672 & 0.001 \\
$\quad$ PLFA composition & 12.18 & 0.635 & 0.014 \\
$\quad$ Microbial functional groups & 16.44 & 0.701 & 0.001 \\
Crop type conversion-induced & & & \\
$\quad$ Soil properties & 0.116 & 0.028 & 0.809 \\
$\quad$ PLFA composition & 0.247 & 0.058 & 0.913 \\
$\quad$ Microbial functional groups & 0.090 & 0.022 & 0.917 \\
\hline
\end{tabular}



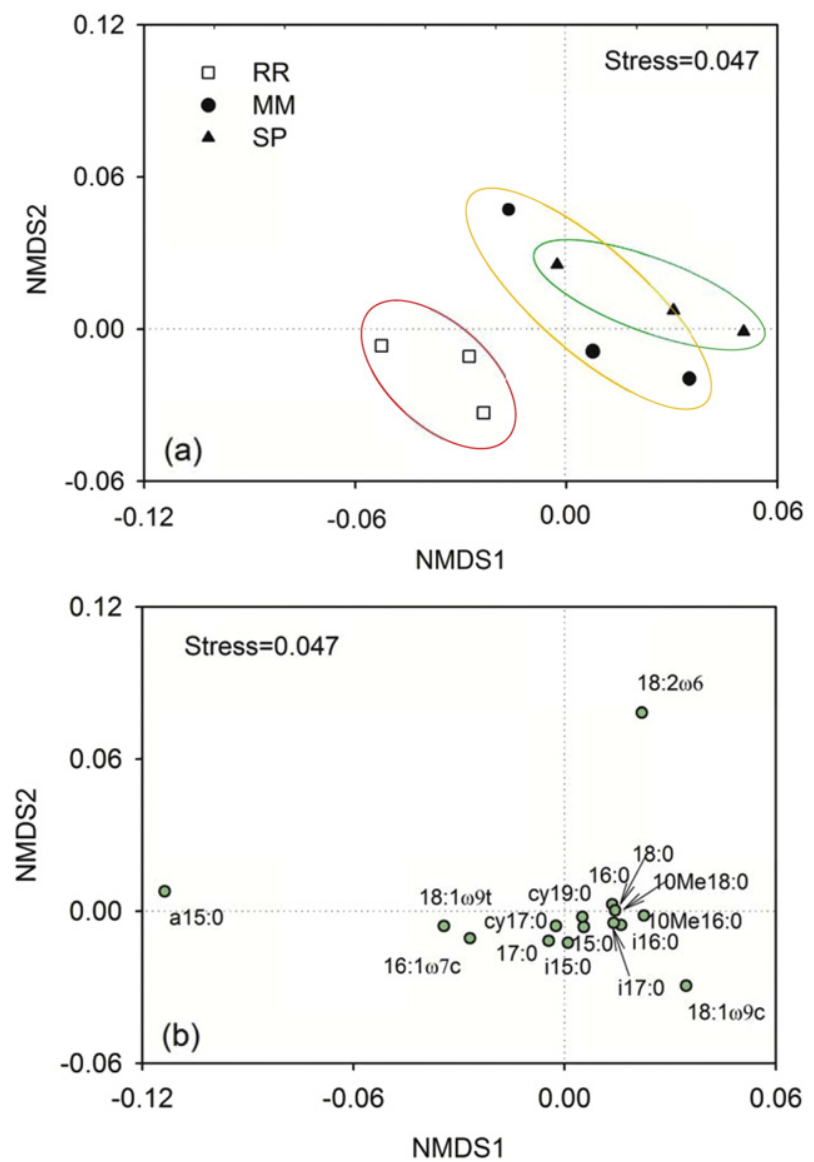

Fig. 1. NMDS of microbial community composition (ng PLFA proportions per g soil). a) Separation of soil samples by land use type. Lines are drawn around the outermost points of each type. b) Distribution of PLFA signatures between land use type. The NMDS analysis was based on 16 PLFA signatures, among which 18:0 and 10Me16:0 overlapped. RR, rice-rice; MM, maize-maize; SP, soybean-peanut.

PLFA patterns suggest that the microbial community composition shifted from a community consisting of predominantly Gram-positive and Gram-negative bacteria to a community that included a relatively greater proportion of fungi after conversion to the drained fields.

\subsection{Microbial functional groups}

The microbial functional groups expressed by the PLFA biomarkers were significantly influenced by land use conversion but not crop type (Fig. 2a and Table 2), and land conversion explained $70.1 \%$ of the variation. Similar to the PLFA composition profiles, the microbial functional group profiles in the drained soils were clearly separated from those of the paddy soils, and the MM and SP profiles were not separated from each other (Fig. 2a). This further consolidated the results that the microbial community profiles were obviously different after paddy conversion to drained fields, but were similar between MM and SP.

The soil total microbial biomass based on the PLFAs ranged from 2.22 to $4.42 \mu \mathrm{g} \mathrm{g}^{-1}$ soil, which decreased significantly after conversion (Fig. 3). The bacterial, G+, G- and actinomycetic biomass also decreased significantly (by $41 \%-57 \%$ ) after the conversion from paddy fields to drained fields (Fig. 3). No significant difference in fungal biomass was found between the different land use types. Additionally, the differences were not significant in the microbial biomass between MM and SP (Fig. 3). The ratios of bacteria, G + and G - to total PLFA decreased significantly, and that of fungi to total PLFA significantly increased after conversion (Fig. 4). This also showed a trend in the community transformation from $\mathrm{G}+$ and $\mathrm{G}-$ to fungi after conversion. The conversion to drained fields significantly increased the soil $\mathrm{F} / \mathrm{B}$, but
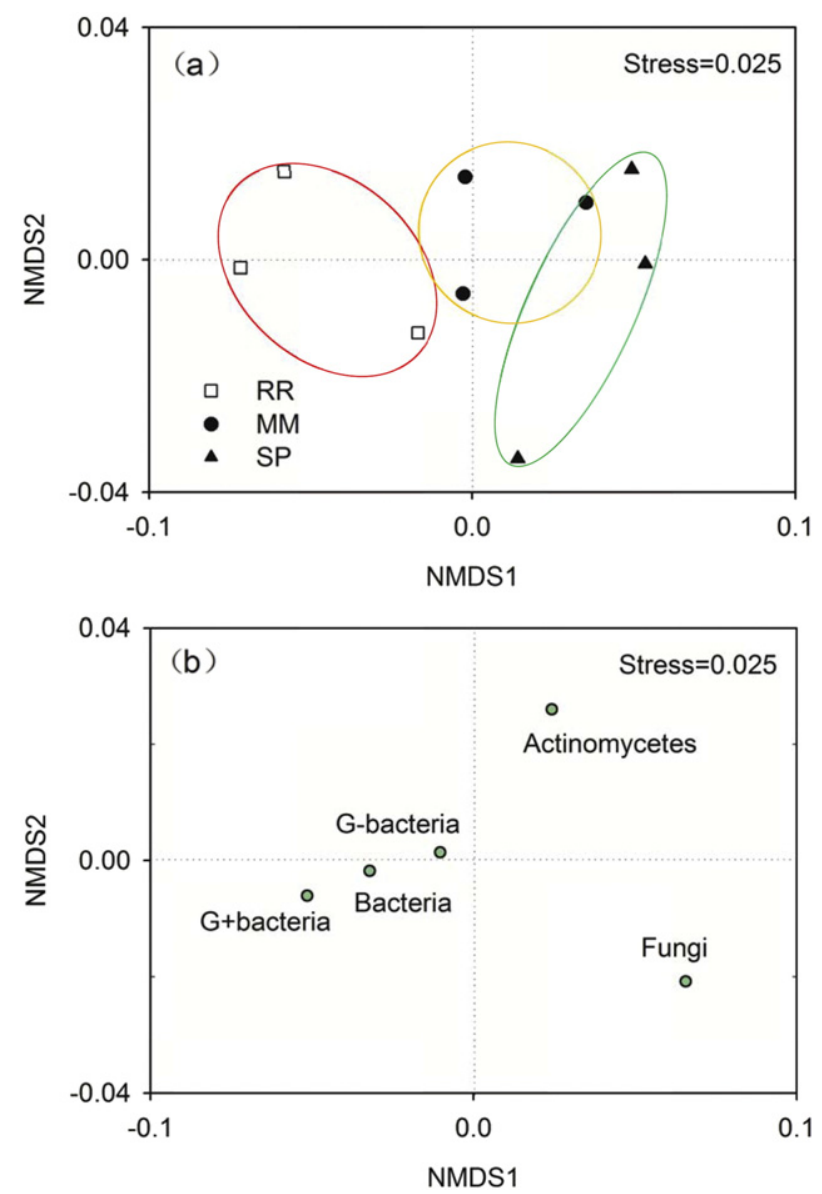

Fig. 2. NMDS of microbial functional groups based on the concentration of the PLFA biomarkers. a) Separation of soil samples by land use types. Lines are drawn around the outermost points of each type. b) Distribution of microbial functional groups between land use type. RR, rice-rice; MM, maize-maize; SP, soybean-peanut.

had no significant effects on the ratios of $\mathrm{G}+/ \mathrm{G}-$ and of cyclopropyl

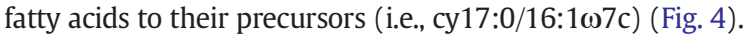

\subsection{Factors influencing soil microbial profiles}

Soil pH had a significant effect on the PLFA composition and microbial functional groups, explaining $61.3 \%$ and $70 \%$ of the variation, respectively (Table 3 ). The relationships between the microbial functional groups and the soil properties are shown in Fig. 5. The high levels of $\mathrm{pH}$ (characteristic of paddy fields) were closely associated with the bacterial, $\mathrm{G}+$ and $\mathrm{G}$ - bacterial biomarkers.

\section{Discussion}

The perMANOVA results showed that land use conversion from paddy fields to drained fields has significant effects on soil properties (Tables 1 and 2). In accordance with our first hypothesis, the recent conversion from paddy fields to drained fields significantly changed the soil properties. These influencing patterns and extents on soil properties were similar for conversed MM and SP, which confirms the role of land use conversion (from paddy fields to drained fields) in altering soil properties (Darilek et al., 2010; Yuan et al., 2015). It was obvious that the soil water content decreased significantly after conversion from RR to MM and SP (Table 1), even though the soil samples were collected at crop harvest after the rice fields had been drying. However, the drained fields were also at the harvest period and no irrigation had been conducted for a long time. 

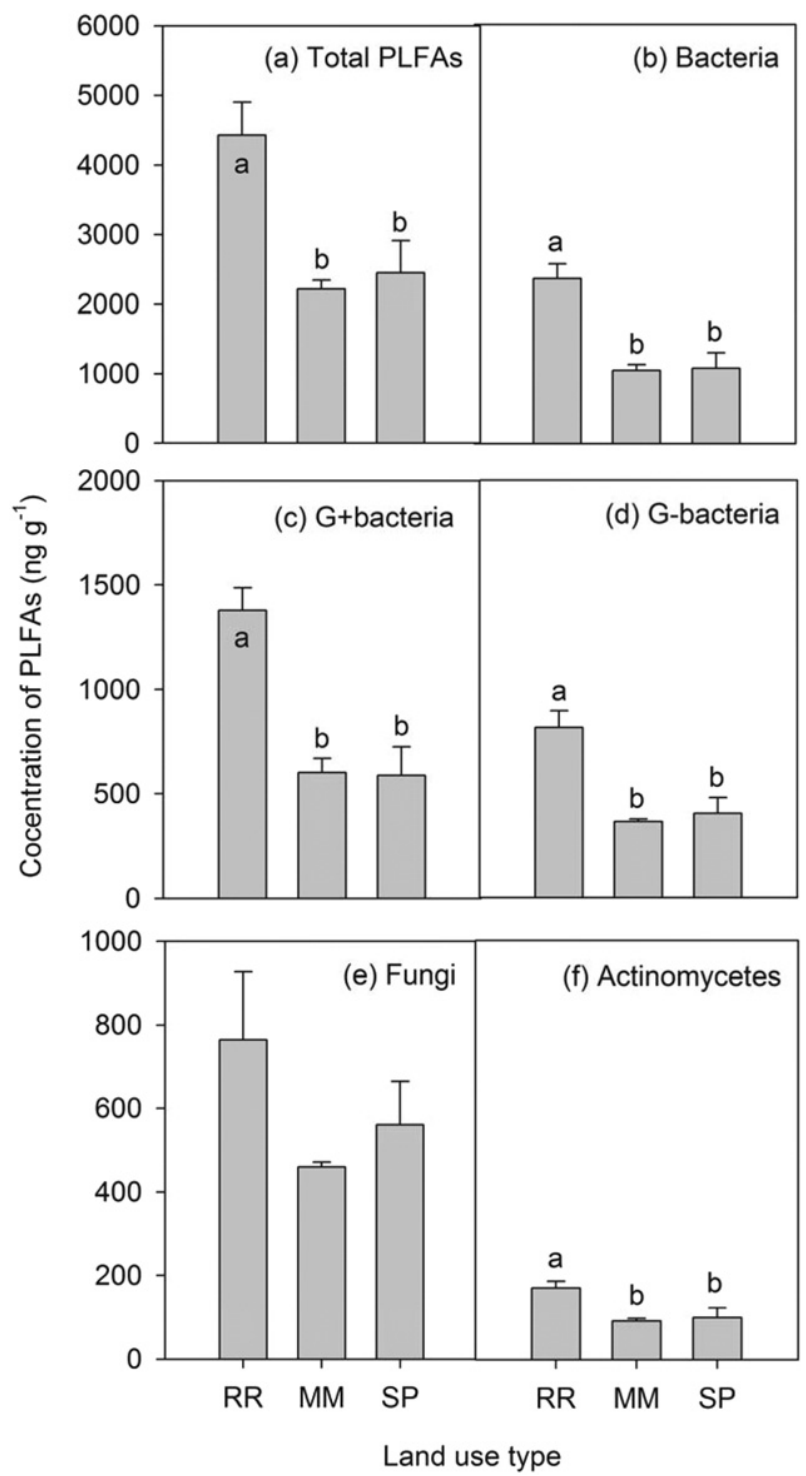

Fig. 3. Concentration of PLFA biomarkers expressed by microbial functional groups under different land use types (mean \pm standard error). RR, rice-rice; MM, maize-maize; SP, soybean-peanut. Different letters indicate significant difference within a functional group $(P<0.05)$

Moreover, due to the intermittent or continuous flooding, the paddy soils were anaerobic, and considerable reduction state substances, e.g., $\mathrm{Mn}^{2+}, \mathrm{Fe}^{2+}, \mathrm{HS}^{-}$and $\mathrm{NH}_{4}^{+}$, had accumulated in these soils. Once a soil is drained and becomes aerobic, the reduction state substances are oxygenized; thus, $\mathrm{H}^{+}$is produced, which then induces a decrease in the $\mathrm{pH}$ (Kögel-Knabner et al., 2010). The soil pH decreased by 0.50 and 0.52 units 2 years after conversion from RR to MM and SP, respectively (Table 1). Darilek et al. (2010) reported that soil pH decreased by 1 unit after conversion from paddy soils to vegetable soils. The site where the current study was performed was located in subtropical China, and the soil had abundant iron oxidants (Yu et al., 2015). It is possible that considerable iron was oxidized in the conversion of the paddy soil to the drained soils, which resulted in a decrease in the $\mathrm{pH}$.

The inorganic N decreased significantly by $55 \%$ after the conversion from the paddy to the drained soils. This was mainly due to the decrease in $\mathrm{NH}_{4}-\mathrm{N}$ in the drained fields. On the one hand, in flooded rice with saturated anaerobic soils, ammonium is the dominant form of available $\mathrm{N}$ which often was oxidized to nitrate in drained aerobic soils (Dai et al., 2010). And nitrate easily directly lost with water flow and denitrified as $\mathrm{N}_{2} \mathrm{O}$ emission to atmosphere in drained fields (Yuan et al., 2016).
Furthermore, the broadcast fertilizer (for rice) and the hole-applied fertilizer (for the other crops) likely caused the differences in the bulk soil nutrients. The N-uptake by plants in the hole application exceeded those of plants in the broadcast application throughout growing period (Kosuge et al., 2001).

The effects of conversion on SOC varied in different studies (Nishimura et al., 2008; Wang et al., 2014; Darilek et al., 2010). In the current study, the soil SOC did not differ significantly between RR and MM or SP (Table 1). Our studies were conducted 2 years after conversion. Maybe a similar SOC balance is acquired between above- and below-ground biomass, as well as inputs from root exudates and outputs from soil organic matter mineralization in RR, MM and SP (Nishimura et al., 2008; Darilek et al., 2010). Crop type, management intensity, environmental, climatic and site conditions, and time after land use change all influenced SOC sequestration (Jobbagy and Jackson, 2000; Murty et al., 2002). To better understand the effects of land use conversion from paddy to drained fields on soil properties, specific and detailed studies based on very similar site conditions are necessary.

The current study showed that after conversion to drained fields, the soil microbial community profiles were significantly different from those in the paddy fields (Figs. 1 and 2). In accordance with our first hypothesis, land use conversion significantly influenced the soil microbial communities. The soil bacterial, $\mathrm{G}+, \mathrm{G}-$ and actinomycetic biomass decreased significantly, but there was no significant change in the fungal biomass following the conversion (Fig. 3). These results are similar to those reported in previous studies (Lin et al., 2004; Sun et al., 2011; Yang and Zhang, 2014) where land use conversion from paddy to drained soils influenced the soil microbial communities and decreased the soil bacterial biomass. The PLFA and microbial functional group patterns suggested a community shift from more Gram-positive and Gramnegative bacteria to a greater proportion of fungi after conversion to the drained fields (Fig. 2b). The variation in the relative content of the microbial functional groups after conversion confirmed these results (Fig. 4). In the first place, after the conversion from the paddy fields to the drained fields, the soil anaerobic environment changed to an aerobic environment, and the soil water content decreased significantly (Table 1). Because soil fungi rely on more aerobic conditions, and aerobic filamentous fungi have variable hyphal networks that can relocate water and nutrient resources by cytoplasm translocation to make them to adapt low water content (Klein and Paschke, 2004). In the next place, pH impacts the community as a result of the narrow $\mathrm{pH}$ tolerance of some prokaryotic taxa (e.g., bacteria). Acidification of the interior of a microbial cell inhibits the activity of most enzymes as well as overall cell metabolism (Beales, 2004). But fungi have a lower area to volume ratio, enabling them to tolerate a more acidic environment than bacteria (Royer-Tardif et al., 2010). This explained why the bacterial biomass decreased significantly and the fungal biomass did not change (no significant differences) after conversion (Figs. 3 and 4).

After conversion from the paddy fields to the drained fields, the soil water status changed and thus the strong relationship between $\mathrm{pH}$ and the soil water content changed $\left(R^{2}=0.604, P=0.014\right.$, Supplementary material, Table S1). The soil pH explained $61.3 \%$ and $70 \%$ of the total variation in the PLFA composition and microbial groups, respectively (Table 3). In accordance with our third hypothesis, $\mathrm{pH}$ was the main driver of the variation in the soil microbial communities. On the one hand, $\mathrm{pH}$ directly influences bacterial and fungal physiology status (Beales, 2004; Royer-Tardif et al., 2010). On the other hand, pH influences nutrient availability and ion toxicity in soils (Zhalnina et al., 2015). In the current study, soil pH was significantly correlated with other soil parameters, such as IN $\left(R^{2}=0.682, P=0.006\right.$, Supplementary material, Table $\mathrm{S} 1$ ). This may suggest $\mathrm{pH}$ regulation of the availability of these nutrients. Our results differed from previous studies. Sheng et al. (2013) showed that the effect of conversion from paddy fields to drained farming on the microbial community composition was probably due mainly to the change in soil water status. Yang and Zhang (2014) observed that soil moisture, organic matter and nitrogen were 

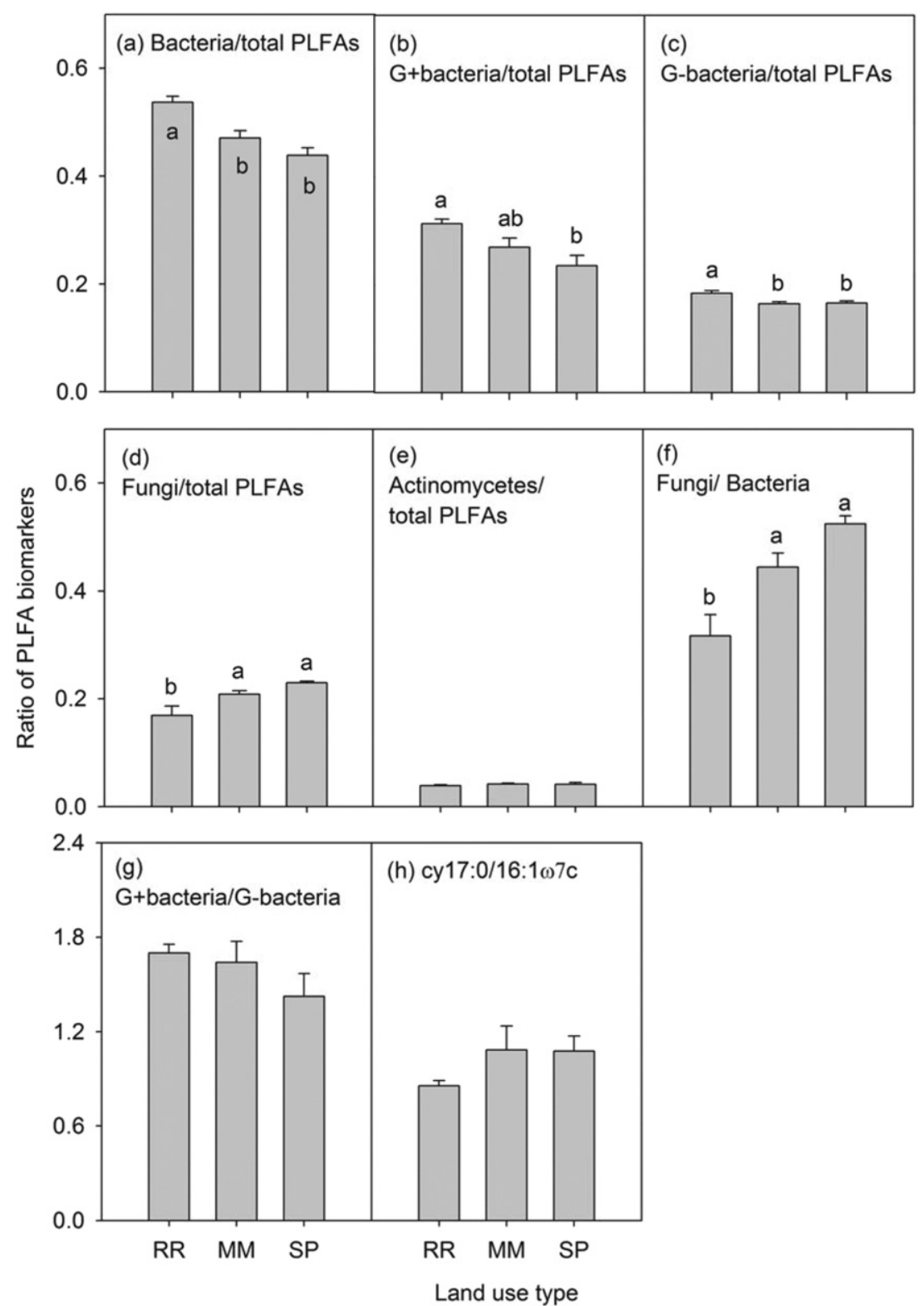

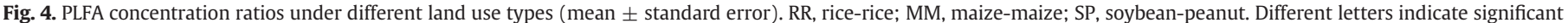
differences within a functional group $(P<0.05)$.

the most important environmental factors influencing microbial community structure. There are two possible reasons for the different relationships between soil properties and microbial communities reported in different studies. First, some previous studies ignored collinearity in

\section{Table 3}

Factors influencing the soil PLFA composition and microbial functional groups according to the perMANOVA results.

\begin{tabular}{|c|c|c|c|c|c|c|}
\hline \multirow[t]{2}{*}{ Soil properties } & \multicolumn{3}{|c|}{ PLFA composition } & \multicolumn{3}{|c|}{ Microbial functional groups } \\
\hline & $\mathrm{F}$ & $\mathrm{R}^{2}$ & $P$-value & $\mathrm{F}$ & $\mathrm{R}^{2}$ & $P$-value \\
\hline $\mathrm{pH}$ & 15.15 & 0.613 & 0.012 & 43.95 & 0.700 & 0.005 \\
\hline WHC & 2.576 & 0.104 & 0.204 & 6.325 & 0.101 & 0.102 \\
\hline SOC & 1.625 & 0.066 & 0.337 & 2.275 & 0.036 & 0.268 \\
\hline $\mathrm{TN}$ & 0.383 & 0.016 & 0.683 & 1.318 & 0.021 & 0.362 \\
\hline $\mathrm{C} / \mathrm{N}$ & 1.079 & 0.044 & 0.396 & 1.164 & 0.019 & 0.418 \\
\hline IN & 1.909 & 0.077 & 0.291 & 5.754 & 0.092 & 0.105 \\
\hline
\end{tabular}

WHC: soil water content; SOC: soil organic carbon; TN: total soil nitrogen; C/N: SOC and TN ratio; IN: inorganic nitrogen.

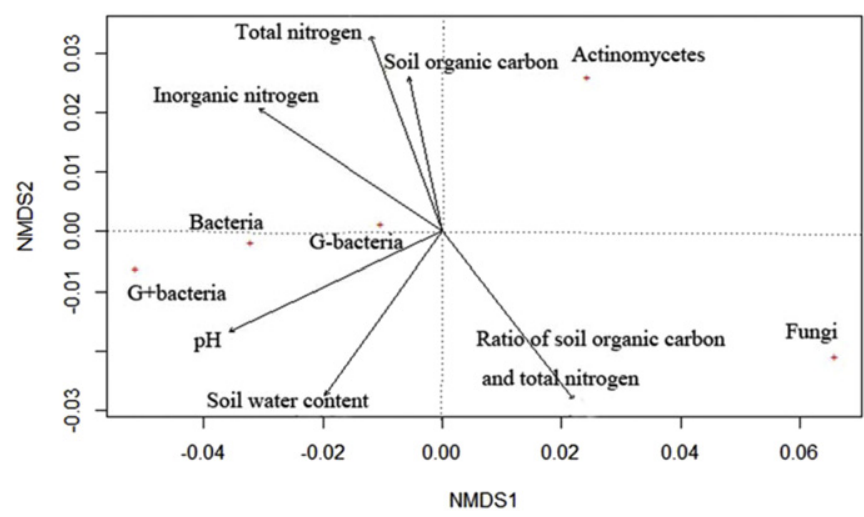

Fig. 5. Distribution of microbial functional groups between land use types and relationships with soil properties. 
the explanatory variables (Dong et al., 2014). For example, Dong et al. (2014) showed that TN, SOC and TP were the major factors explaining the variations in PLFAs under different fertilizer applications, but both TN and SOC, and TP and TN were significantly positively correlated. Therefore, the real factors were easily masked by other dependent factors. Second, the studies were conducted under different land use type in broad region which possibly could produce the various relationships between microbial communities and soil properties (Lisboa et al., 2014; Williams et al., 2013).

Due to the decrease in bacteria, the fungal/bacterial ratio increased significantly after conversion (Fig. 4). This is consistent with the results presented by Yuan et al. (2015). It was noted that a higher fungal/bacterial ratio indicated better sustainability because fungi have a greater growth yield efficiency compared with bacteria, and thus have slow $\mathrm{C}$ turnover (Thiet et al., 2006). However, microbes growing in a low pH environment showed increased ratios of cyclopropyl PLFAs to their monoenoic precursors (Ratledge and Wilkinson, 1988; Ying et al.,

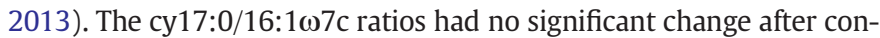
version to the drained fields (Fig. 4), which indicated that the decrease in soil $\mathrm{pH}$ after conversion did not create a more stressful and less favorable environment for the soil microbial communities. This is agreed to the $F / B$ and $c y 17: 0 / 16: 1 \omega 7 c$ results for the sustainability of the drained fields.

In our study, MM and SP had no significant effects on the bulk soil PLFA composition and microbial groups (Figs. 1 and 4). In accordance with our second hypothesis, conversion to MM and SP had similar effects on the soil microbial community composition in the initial years after land conversion. Crop species could not create its bulk soil microbial legacies due to only 2 years after conversion to MM and SP (Kulmatiski and Beard, 2011). Rhizosphere microbial communities are expected to reflect current plant growth because microbes can respond to specific root exudates produced by different plant species within hours (Sanon et al., 2009). However, it is likely that the effects of plant composition are limited to the zones that are adjacent to plant roots, and microbial communities in bulk soil are largely unaffected. Drenovsky et al. (2010) showed that the microbial community composition was more related to differences in land use (e.g., tillage and irrigation regimes) than plant type. Massenssini et al. (2015) also reported that soil chemical characteristics and not plant species identity was the main factor defining the structure of the soil microbial communities.

\section{Conclusions}

The results showed that the changes of anaerobic to aerobic conditions from paddy soils to drained soils but not of crop type significantly influenced the soil properties and microbial communities during the initial conversion. Soil microbial communities shifted from $G+$ and $\mathrm{G}$ - to fungi after conversion, in which soil $\mathrm{pH}$ was the key driver for the variations in the soil microbial communities. It is important for soil models to predict the microbial responses to land use conversion from anaerobic to aerobic conditions. And the subsequent direct and indirect effects on microbial functionality will be key in predicting how ecosystem processes change as plant species shift and soil environment change during land use conversion.

Supplementary data to this article can be found online at http://dx. doi.org/10.1016/j.catena.2016.08.012.

\section{Acknowledgements}

This study was supported by the National Basic Research Program of China (973 Program, 2012CB417103), the National Natural Science Foundation of China (41001179) and the Strategic Science Plan of the Institute of Geographic Sciences and Natural Resources Research (2012ZD004). The authors also thank the academic editor and anonymous reviewers for their constructive comments, which helped to improve the manuscript.

\section{References}

Alberti, G., Vedove, G.D., Zuliani, M., Peressotti, A., Castaldi, S., Zerbi, G., 2010. Changes in $\mathrm{CO}_{2}$ emissions after crop conversion from continuous maize to alfalfa. Agric. Ecosyst. Environ. 136, 139-147.

Arevalo, C.B.M., Bhatti, J.S., Chang, S.X., Sidders, D., 2011. Land use change effects on ecosystem carbon balance: from agricultural to hybrid poplar plantation. Agric. Ecosyst. Environ. 141, 342-349.

Beales, N., 2004. Adaptation of microorganisms to cold temperatures, weak acid preservatives, low pH, and osmotic stress: a review. Compr. Rev. Food Sci. Food Saf. 3, 1-20.

Bossio, D.A., Girvan, M.S., Verchot, L., Bullimore, J., Borelli, T., Albrecht, A., Scow, K.M., Ball, A.S., Pretty, J.N., Osborn, A.M., 2005. Soil microbial community response to land use change in an agricultural landscape of Western Kenya. Microb. Ecol. 49 (1), 50-62.

Bossio, D.A., Scow, K.M., Gunapala, N., Graham, K.J., 1998. Determinants of soil microbial communities: effects of agricultural management, season, and soil type on phosphoipid fatty acid profiles. Microb. Ecol. 36, 1-12.

Creamer, C.A., de Menezes, A.B., Krull, E.S., Sanderman, J., Newton-Walters, R., Farrell, M. 2015. Microbial community structure mediates response of soil C decomposition to litter addition and warming. Soil Biol. Biochem. 80, 175-188.

Dai, X.Q., Zhang, H.Y., Spiertz, J.H.J., Yu, J., Xie, G.H., Bouman, B.A.M., 2010. Crop response of aerobic rice and winter wheat to nitrogen, phosphorus and potassium in a double cropping system. Nutr. Cycl. Agroecosyst. 86, 301-315.

Darilek, J.L., Huang, B., Li, D.C., Wang, Z.G., Zhao, Y.C., Sun, W.X., Shi, X.Z., 2010. Effect of land use conversion from rice paddies to vegetable fields on soil phosphorus fractions. Pedosphere 20 (2), 137-145.

Dong, W.Y., Zhang, X.Y., Dai, X.Q., Fu, X.L., Yang, F.T., Liu, X.Y., Sun, X.M., Wen, X.F., Schaeffer, S., 2014. Changes in soil microbial community composition in response to fertilization of paddy soils in subtropical China. Appl. Soil Ecol. 84, 140-147.

Drenovsky, R.E., Steenwerth, K.L., Jackson, L.E., Scow, K.M., 2010. Land use and climatic factors structure regional patterns in soil microbial communities. Glob. Ecol. Biogeogr. 19, 27-39.

Frostegård, A., Bååth, E., 1996. The use of phospholipid fatty acid analysis to estimate bacterial and fungal biomass in soil. Biol. Fertil. Soils 22, 59-65.

Frostegård, A., Bååth, E., Tunlid, A., 1993. Shifts in the structure of soil microbial communities in limed forests as revealed by phospholipid fatty acid analysis. Soil Biol Biochem. 25, 723-730.

Frostegård, A., Tunlid, A., Bååth, E., 2011. Use and misuse of PLFA measurements in soils. Soil Biol. Biochem. 43, 1621-1625.

Houghton, R.A., Hackler, J.L., Lawrence, K.T., 1999. The US carbon budget: contributions from land use change. Science 285, 574-578.

Jangid, K., Williams, M.A., Franzluebbers, A.J., 2011. Land-use history has a stronger impact on soil microbial community composition than aboveground vegetation and soil properties. Soil Biol. Biochem. 43 (10), 2184-2193.

Jobbagy, E.G., Jackson, R.B., 2000. The vertical distribution of soil organic carbon and its relation to climate and vegetation. Ecol. Appl. 10, 423-436.

Klein, D.A., Paschke, M.W., 2004. Filamentous fungi: the indeterminate lifestyle and microbial ecology. Microb. Ecol. 47, 224-235.

Kögel-Knabner, I., Amelung, W., Cao, Z., Fiedler, S., Frenzel, P., Jahn, R., Schloter, M., 2010. Biogeochemistry of paddy soils. Geoderma 157, 1-14.

Kosuge, S. Higashi, T., Saigusa, M., 2001. Effects of fertilization methods on N-uptake, vegetative growth and yield of forcing strawberry. J. Japan Soc. Hortic. Sci. 70, 616-621.

Kulmatiski, A., Beard, K.H., 2011. Long-term plant growth legacies overwhelm short-term plant growth effects on soil microbial community structure. Soil Biol. Biochem. 43, 823-830.

Lauber, C.L., Strickland, M.S., Bradford, M.A., Fierer, N., 2008. The influence of soil properties on the structure of bacterial and fungal communities across land-use types. Soi Biol. Biochem. 40 (9), 2407-2415.

Lin, X.G., Yin, R., Zhang, H.Y., Huang, J.F., Chen, R.R., Cao, Z.H., 2004. Changes of soil microbiological properties caused by land use changing from rice-wheat rotation to vegetable cultivation. Environ. Geochem. Health 26, 119-128.

Lisboa, F.J.G., Chaer, G.M., Fernandes, M.F., Berbara, R.L.L., Madari, B.E., 2014. The match between microbial community structure and soil properties is modulated by land use types and sample origin within an integrated agroecosystem. Soil Biol. Biochem. 78, 97-108.

Massenssini, A.M., Bonduki, V.H.A., Melo, C.A.D., Totola, M.R., Ferreira, F.A., Costa, M.D., 2015. Relative importance of soil physic-chemical characteristics and plant species identity to the determination of soil microbial community structure. Appl. Soil Ecol. 91, 8-15.

Moore-Kucera, J., Dick, R.P., 2008. PLFA profiling of microbial community structure and seasonal shifts in soils of a Douglas-fir chronosequence. Microb. Ecol. 55, 500-511.

Murty, D., Kirschbaum, M.U.F., McMurtrie, R.E., McGilvray, A., 2002. Does conversion of forest to agricultural land change soil carbon and nitrogen? A review of the literature. Glob. Chang. Biol. 8, 105-123.

Nishimura, S., Yonemura, S., Sawamoto, T., Shirato, Y., Akiyama, H., Sudo, S., Yagi, K., 2008 Effect of land use change from paddy rice cultivation to upland crop cultivation on soil carbon budget of a cropland in Japan. Agric. Ecosyst. Environ. 125, 9-20.

Ratledge, C., Wilkinson, S.G., 1988. Microbial lipids, vol 1. Academic Press Inc, San Diego.

$\mathrm{R}$ development core team, 2009. R: a language and environment for statistical computing. R Foundation for Statistical computing, Vienna.

Robertson, G.P., Paul, E.A., Hardwood, R.R., 2000. Greenhouse gases in intensive agriculture: contributions of individual gases to the radiative forcing of the atmosphere. Science 289, 1922-1925.

Royer-Tardif, S., Bradley, R.L., Parsons, W.F.J., 2010. Evidence that plant diversity and site productivity confer stability to forest floor microbial biomass. Soil Biol. Biochem. 42 813-821. 
Sanon, A., Andrianjaka, Z.N., Prin, Y., Bally, R., Thioulouse, J., Comte, G., Duponnois, R., 2009. Rhizosphere microbiota interfers with plant-plant interactions. Plant Soil 321 259-278.

Sheng, R., Meng, D.L., Wu, M.N., 2013. Effect of agricultural land use change on community composition of bacteria and ammonia oxidizers. J. Soils Sediments 13 (7) 1246-1256.

Sun, B., Dong, Z.X., Zhang, X.X., Li, Y., Cao, H., Cui, Z.L., 2011. Rice to vegetables: short- versus long-term impact of land-use change on the indigenous soil microbial community. Microb. Ecol. 62, 474-485.

Thiet, R.K., Frey, S.D., Six, J., 2006. Do growth yield effiencies differ between soil microbia communities differing in fungal:bacterial ratios? Reality check and methodological issues. Soil Biol. Biochem. 38, 195-203.

Tong, C., Hall, C.A.S., Wang, H., 2003. Land use change in rice, wheat and maize production in China (1961-1998). Agric. Ecosyst. Environ. 95, 523-536.

Wang, H., Guan, D., Zhang, R., Chen, Y., Hu, Y., Xiao, L., 2014. Soil aggregates and organic carbon affected by the land use change from rice paddy to vegetable field. Ecol. Eng. 70, 206-211.

Williams, A., Brjesson, G., Hedlund, K., 2013. The effects of 55 years of different inorganic fertilizer regimes on soil properties and microbial community composition. Soil Biol. Biochem. 67, 41-46.
Yang, D., Zhang, M., 2014. Effects of land-use conversion from paddy field to orchard farm on soil microbial genetic diversity and community structure. Eur. J. Soil Biol. 64, 30-39.

Ying, J.Y., Zhang, L.M., Wei, W.X., He, J.Z., 2013. Effects of land utilization patterns on soil microbial communities in an acid red soil based on DNA and PLFA analyses. J. Soils Sediments 13, 1223-1231.

Yu, X., Fu, Y., Brookes, P.C., Lu, S., 2015. Insights into the formation process and environmental fingerprints of iron-manganese nodules in subtropical China. Soil Sci. Soc. Am. J. 79, 1101-1114

Yuan, Y., Dai, X.Q., Wang, H.M., Xu, M., Fu, X.L., Yang, F.T., 2016. Effect of land-use conversion from double rice cropping to vegetables on methane and nitrous oxide fluxes in southern China. PLoS One 11 (5), e0155926.

Yuan, Y., Dai, X.Q., Xu, M., Wang, H.M., Fu, X.L., Yang, F.T., 2015. Responses of microbial community structure to land-use conversion and fertilization in southern China. Eur. J. Soil Biol. 70, 1-6.

Zhalnina, K., Dias, R., de Quadros, P.D., Davis-Richardson, A., Camargo, F.A.O., Clark, I.M., 2015. Soil pH determines microbial diversity and composition in the park grass experiment. Microb. Ecol. 69, 395-406.

Zhang, X., Wang, D., Fang, F., 2005. Food safety and rice production in China. Resour. Agr. Modern. 26 (1), 85-88. 